\section{Knowledge management best practices among rice farmers in selected areas of Tanzania}

Journal of Librarianship and Information Science 2020, Vol. 52(2) 33I-344

(C) The Author(s) 2019 Article reuse guidelines: sagepub.com/journals-permissions DOI: 10.1177/0961000619856087 journals.sagepub.com/home/lis

(S)AGE

\author{
Wulystan Pius Mtega \\ Sokoine University of Agriculture, United Republic of Tanzania
}

\author{
Mpho Ngoepe \\ University of South Africa, South Africa
}

\begin{abstract}
For improved rice production, farmers need access to timely and relevant knowledge at each stage of the rice-cropping calendar. To understand how farmers involve themselves in acquiring and sharing agricultural knowledge, this study investigates how knowledge management best practices can be enhanced among rice farmers in selected rural areas of Tanzania. Data were collected from 226 rice farmers in three districts (Kilombero, Kilosa and Mvomero) of the Morogoro region in Tanzania. Findings from structured questionnaires and focused group discussion indicate that rice farmers accessed, shared and used agricultural knowledge. It was found that individual, institutional and knowledge factors influence the performance of agricultural knowledge management activities. For enhancing effective agricultural knowledge management, it is important to take into consideration the knowledge management best practices, which include developing effective knowledge infrastructure, involving different stakeholders and using appropriate information and communications technology tools in enhancing access to knowledge. It is concluded that effective knowledge management activities increase the level of adoption of agricultural innovations. It is recommended that the proposed agricultural knowledge management best practices be adapted for improving rice production.
\end{abstract}

\title{
Keywords
}

Agricultural knowledge, agricultural knowledge management best practices, knowledge management, knowledge management activities, rice production, Tanzania

\section{Introduction}

The agriculture sector is the backbone of Tanzania's economy. It employs about $80 \%$ of the national labour force (Nkuba et al., 2016). Maize, rice, beans and millet are the main crops produced in Tanzania (Mkonda and He, 2016). Rice is the second most important food and commercial crop after maize; it is among the major sources of employment, income and food security for farming households (Lyatuu et al., 2016). Though small-scale farmers are the major rice producers in the country, Tanzania is the second largest producer of rice in Southern Africa, after Madagascar (Terdoo and Feola, 2016).

In agriculture, access to knowledge increases adoption of improved agricultural practices (Sanchez, 2002), hence improving agricultural productivity. Transfer of knowledge enhances knowledge accessibility among different actors and usage of knowledge improves individual understanding and facilitates rational decision-making. Knowledge acquisition, knowledge exchange, and knowledge usage are among the common practices in knowledge management (Jayasingam et al., 2010).

\section{Statement of the problem}

Rice farmers in Tanzania experience inadequate access to agricultural knowledge more than other agricultural stakeholders (Bernard et al., 2014; Nkuba et al., 2016).

\section{Corresponding author:}

Wulystan Pius Mtega, Reference and Community Information Services, Sokoine University of Agriulture, PO Box 3022, Morogoro, United Republic of Tanzania.

Email:wmtega@gmail.com 
This situation has resulted in low adoption of improved seeds, poor crop husbandry practices, low management of plant diseases, low ability to cope with climate change, low rice productivity and low market prices (Nkuba et al., 2016; Schut et al., 2015; Stadlinger et al., 2011), thus affecting individual income and contributing to farmers' poverty. Moreover, due to a lack of knowledge, some rice farmers fail to use pesticides properly and dispose of pesticide containers inappropriately, causing environmental pollution (Stadlinger et al., 2011).

Knowledge is a factor in production, together with land, capital and labour. Its accessibility and usage enhances decision-making about how to allocate other factors of production (Richter et al., 2013) and enhances adoption of good agricultural practices among farmers. When stakeholders (including farmers) in rice production involve themselves in performing agricultural knowledge management activities, they enhance access to knowledge (Kamarudin et al., 2015), resulting in optimised rice production and increased profits.

\section{Objectives of the study}

This study investigates how knowledge management best practices can be enhanced among rice farmers, with the aim to increase production in selected rural areas of Tanzania. This study specifically:

1. reports agricultural knowledge management activities in which farmers frequently involve themselves;

2. reports factors influencing farmers' involvements in agricultural knowledge management activities;

3. suggests agricultural knowledge management best practices needed for increasing the accessibility and usage of knowledge among farmers.

\section{Literature review}

Knowledge management involves different activities performed to enhance accessibility and usage of knowledge. It also comprises the strategies and methods employed to generate and leverage knowledge (Krudys et al., 2011).

\section{Agricultural knowledge management activities}

Knowledge management involves several sets of activities performed so as to enhance access to and usage of knowledge. Such activities include creating/capturing knowledge, organising it, storing it and using it (Richter et al., 2013). When conducted effectively, knowledge management activities increase individual performance, provide the workforce with adequate skills, and enhance rational decisions regarding production processes. Organisations that grasp knowledge management activities effectively are in the best position to attain a competitive advantage (Claver-Cortés et al., 2007).

Agricultural production is knowledge intensive because it involves many risks such as pest and disease outbreaks, extreme weather events and market shocks (Harvey et al., 2014), which influence what and when to produce. Dealing with risks requires adequate access to relevant knowledge. Agricultural knowledge creation in rice production involves different stakeholders. While rice farmers share and create knowledge through cumulative experience in farming activities (Singh et al., 2014), agricultural research institutes play a major role in generating new agricultural knowledge and developments. Through agricultural extension and advisory systems, farmers can have access to generated knowledge (Munyua and Stilwell, 2013). When created, agricultural knowledge may be organised and repackaged for easy consumption. Repackaging involves selection, analysing, processing and translating information with a view to communicating a message in a convenient and effective form to a target audience defined for the purpose (Dongardive, 2013). Well-repackaged information can potentially communicate the intended knowledge to the target audience.

Depending on the agricultural knowledge system used, knowledge can be stored as hard copy (paper-based system) or as soft copy (computer-based system). Compared to a computer-based system, a paper-based system is considered to be inefficient, slow, laborious, difficult in terms of managing resources and consumes more space (Labrique et al., 2013). Compared to paper-based systems, electronic devices used for purposes of storing knowledge are considered to be more efficient, utilise little space and do not involve more labourers in managing knowledge (Stausberg et al., 2003).

Enhancing access to relevant knowledge throughout the rice value chain for each stage of the rice-cropping calendar is important for facilitating rational decisions regarding rice production and post-harvest handling. From Jayasingam et al. (2010), knowledge acquisition, knowledge exchange, and knowledge usage influence the performance of knowledge management activities. In Tanzania, most studies on agricultural knowledge management have concentrated on farmers' knowledge needs (Lwoga, 2010; Lwoga et al., 2011; Mtega et al., 2016). This research study addresses a gap to explore a broad range of farmers' involvement in agricultural knowledge management, which may contribute to accessibility of agricultural knowledge.

\section{Factors influencing the effectiveness of knowledge management activities}

Culture, technology used for knowledge management, elements and components of knowledge management system (people-centred against technology-centred knowledge management system) and frameworks supporting 


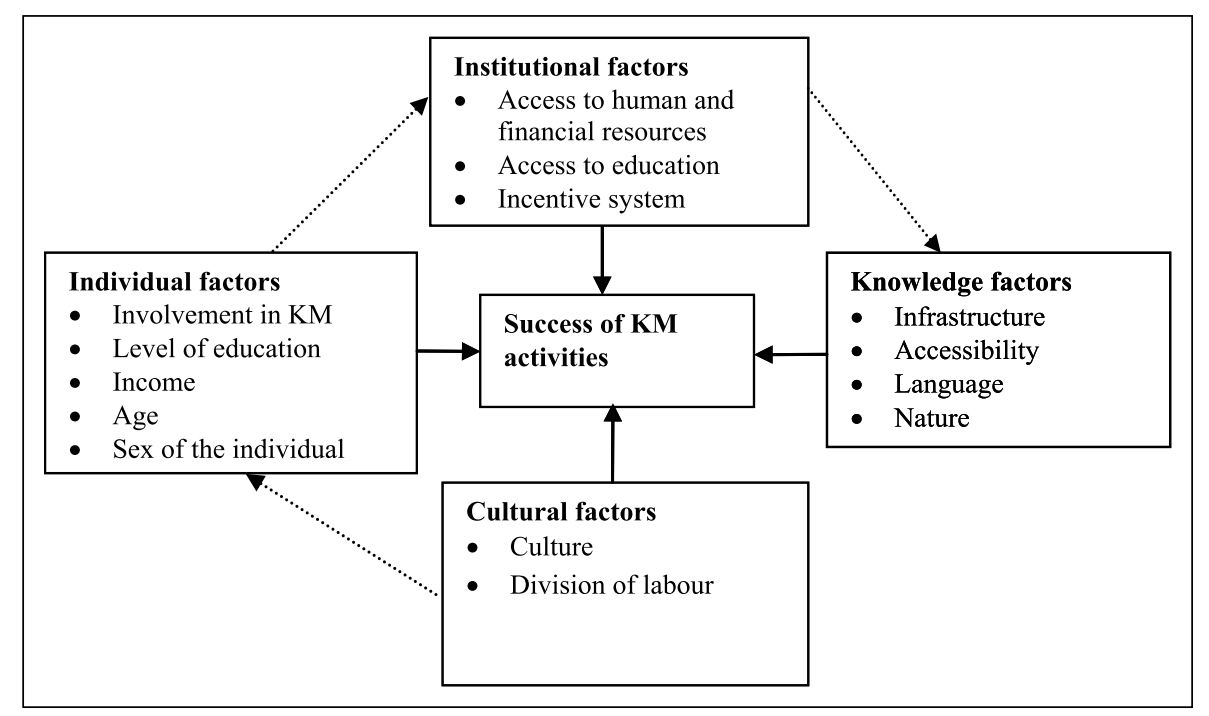

Figure I. Research conceptual framework.

knowledge management are among the factors influencing knowledge management activities (Hameed and Badii, 2012; Jauniškytè and Kvaraciejutè, 2008). Other factors include employee training, employee involvement, teamwork, employee empowerment, top management leadership and commitment, organisational constraints, information system infrastructure, performance measurement, egalitarian culture, benchmarking and knowledge structure (Butler and Murphy, 2007).

Farming communities like other agricultural institutions and organisations are involved in performing different agricultural knowledge management activities. Studies (Lwoga et al., 2011; Mtega et al., 2013, 2016; National Bureau of Statistics (NBS), 2013; Schut et al., 2015; Stadlinger et al., 2011) conducted in Tanzania show that farmers are only involved in performing some of the agricultural knowledge activities. They indicate that farmers are mainly involved in accessing, sharing and using agricultural knowledge (Schut et al., 2015; Stadlinger et al., 2011). Farmers are involved in creating indigenous knowledge (this is the type of knowledge possessed by local communities; it is used to resolve local problems for the survival of the community (Moahi, 2012)) which is considered to be among the rich forms of knowledge created by indigenous people (including local farmers) in rural areas (Mercer et al., 2009). In agriculture, farming experience is the main source of indigenous knowledge. Usage of indigenous knowledge in agriculture is always associated with traditional farming systems which in most cases have not transformed farming.

Having an adequate understanding of factors that influences performance of agricultural knowledge activities among farmers is important for enhancing access to agricultural knowledge. Studies (Dharmarathna and Weerakoon, 2016; Elly et al., 2013; Nonaka et al., 2000) conducted in different countries have concentrated on factors influencing performance of knowledge management activities in formal institutions. Therefore, this paper creates an understanding of contextual factors influencing the performance of knowledge management activities among rice farmers.

\section{Research conceptual framework}

Figure 1 illustrates the research conceptual framework generated to guide the study. It is based on factors influencing the performance of agricultural knowledge management activities. Both institutional, individual, cultural and knowledge factors influence the effectiveness of performance of agricultural knowledge management activities.

\section{Research methodology}

This study was conducted in the Morogoro region of Tanzania. Data from the national census conducted in 2012 indicate that the region had a total of 2,218,492 people $(1,093,302$ males and 1,125,190 females) with a total of 385,260 households; among them, 378,400 (98.2\%) households which were directly involved in agricultural production (National Bureau of Statistics (NBS), 2013).

Morogoro region is endowed with abundant agricultural land suitable for crop production and has a climate that is favourable for agriculture and other economic investments. From among the total six district councils, Kilombero, Kilosa and Mvomero were involved in this study. All three district councils are homogenous in terms of the major crops grown, availability of agricultural research institutes and information and communication technology (ICT) infrastructure. The ICT infrastructure for this study included the conventional or traditional ICT 
Table I Sampling framework and sample size.

\begin{tabular}{llcr}
\hline District & Village & Rice farmers & Sample size \\
\hline Kilosa & Chanzuru & 892 & 13 \\
& Kimamba B & 1448 & 22 \\
Mvomero & Rudewa Batini & 1196 & 18 \\
& Mlimba A & 1658 & 25 \\
& Hembeti & 1451 & 21 \\
Kilombero & Wami Dakawa & 2408 & 36 \\
& Mvomero & 1666 & 26 \\
Total & Michenga & 1437 & 19 \\
\hline
\end{tabular}

Source: National Bureau of Statistics (NBS), 2013.

Table 2. Demographic characteristics of respondents.

\begin{tabular}{|c|c|c|c|}
\hline \multicolumn{4}{|c|}{ Age by sex of respondents } \\
\hline \multirow[t]{2}{*}{ Age groups } & \multicolumn{2}{|c|}{ Sex of the respondent } & \multirow[t]{2}{*}{ Total } \\
\hline & Male & Female & \\
\hline 15 to 25 & $7(6.3 \%)$ & $9(7.8 \%)$ & $16(7.1 \%)$ \\
\hline 26 to 35 & $28(25.2 \%)$ & $30(26.1 \%)$ & $58(25.7 \%)$ \\
\hline 36 to 45 & $27(24.3 \%)$ & $26(22.6 \%)$ & $53(23.5 \%)$ \\
\hline 46 to 55 & $18(16.2 \%)$ & $12(10.4 \%)$ & $30(13.3 \%)$ \\
\hline 55 to 65 & $16(14.4 \%)$ & $20(17.4 \%)$ & $36(15.9 \%)$ \\
\hline 66 and above & $15(13.5 \%)$ & $18(15.7 \%)$ & $33(14.6 \%)$ \\
\hline Total & I I I (I00\%) & I 15 ( $100 \%)$ & $226(100 \%)$ \\
\hline
\end{tabular}

(radio and television) and contemporary or modern ICT (computer, Internet and mobile phone) (Alsuraihi, 2013; Olaniyi, 2013). To select respondents, a sampling frame (list of people forming the population) of rice farmers from each village was made. A study by Bartlett et al. (2001) proposed a table estimating the sample size according to population size. Based on these estimates, a sample size of 226 rice farmers was determined. Simple random sampling technique was used to select the sample from the population of rice farmers from the nine villages (see Table 1). The technique was selected because it gives equal probability of each unit to be included in the sample and can enhance generalisation of results.

The study used a structured questionnaire and a focus discussion guide in data collection. A structured questionnaire with open- and closed-ended questions was piloted and administered to the 226 rice farmers and all responded to the questionnaire making a $100 \%$ response rate. Three focus group discussions were conducted (one in each district) to supplement data collected through structured questionnaires. Face-to-face interview sessions were arranged for data collection. Data collected were edited, classified, cleaned and entered in the Statistical Package for Social Sciences (SPSS) which facilitated its analysis. The SPSS facilitated the generation of frequencies, percentages and tables. Qualitative data collected were analysed through content analysis and summarised into descriptions and explanations.

\section{Findings}

Both male and female rice farmers were involved in the study. Findings in Table 2 indicate that 111 (49.1\%) of the respondents were males while $115(50.9 \%)$ were females. The majority of the respondents fell within two age groups: the age group of 26 to 35 with $58(25.7 \%)$ respondents, followed by the age group of 36 to 45 with 53 $(23.5 \%)$ respondents. Other age groups had fewer than 40 respondents.

\section{Agricultural knowledge management activities of the farmers}

Respondents were asked to list their agricultural management activities. The findings in Table 3 indicate that 145 $(64.2 \%)$ rice farmers mentioned access to agricultural knowledge while all used agricultural knowledge. Others $(212,93.8 \%)$ said that they shared agricultural knowledge with others while 211 (93.4\%) mentioned observing farmrelated problems. Findings indicate that $152(67.3 \%)$ rice 
Table 3. Agricultural knowledge management activities according to sex of the farmers.

\begin{tabular}{|c|c|c|c|}
\hline \multirow[t]{2}{*}{ Knowledge management activity } & \multicolumn{3}{|c|}{ Frequency of respondents performing it } \\
\hline & Male $n=I I \mid$ & Female $n=115$ & Total $n=226$ \\
\hline Accessing knowledge & $80(72.1 \%)$ & $65(56.5 \%)$ & 145 (64.2\%) \\
\hline Using knowledge & III (I00\%) & $115(100 \%)$ & $226(100 \%)$ \\
\hline Sharing knowledge & $106(95.5 \%)$ & $106(92.2 \%)$ & $212(93.8 \%)$ \\
\hline Observing farm-related problems & $102(91.9 \%)$ & 109 (94.8\%) & $211(93.4 \%)$ \\
\hline Solving farm-related problem & $73(66.4 \%)$ & $79(69.3 \%)$ & $152(67.3 \%)$ \\
\hline Reporting of observed problems & 78 (73.6\%) & $69(63.9 \%)$ & 147 (68.7\%) \\
\hline
\end{tabular}

Table 4. Agricultural knowledge management activities performed by rice farmers based on their farming experience.

\begin{tabular}{|c|c|c|c|c|c|c|}
\hline \multirow[t]{2}{*}{ Knowledge management activity } & \multicolumn{6}{|c|}{ Years in farming } \\
\hline & $15-25$ & $26-35$ & $36-45$ & $46-55$ & $56-65$ & $>66$ \\
\hline Accessing knowledge & $\begin{array}{l}15 \\
93.8 \%\end{array}$ & $\begin{array}{l}56 \\
96.6 \%\end{array}$ & $\begin{array}{l}50 \\
94.3 \%\end{array}$ & $\begin{array}{l}28 \\
93.3 \%\end{array}$ & $\begin{array}{l}36 \\
100 \%\end{array}$ & $\begin{array}{l}26 \\
78 \%\end{array}$ \\
\hline Using knowledge & $\begin{array}{l}16 \\
100 \%\end{array}$ & $\begin{array}{l}58 \\
100 \%\end{array}$ & $\begin{array}{l}53 \\
100 \%\end{array}$ & $\begin{array}{l}30 \\
100 \%\end{array}$ & $\begin{array}{l}36 \\
100 \%\end{array}$ & $\begin{array}{l}33 \\
100 \%\end{array}$ \\
\hline Sharing knowledge & $\begin{array}{l}16 \\
100 \%\end{array}$ & $\begin{array}{l}55 \\
94.8 \%\end{array}$ & $\begin{array}{l}48 \\
90.6 \%\end{array}$ & $\begin{array}{l}29 \\
96.7 \%\end{array}$ & $\begin{array}{l}32 \\
88.9 \%\end{array}$ & $\begin{array}{l}32 \\
97 \%\end{array}$ \\
\hline Observing farm-related problems & $\begin{array}{l}16 \\
100 \%\end{array}$ & $\begin{array}{l}55 \\
94.8 \%\end{array}$ & $\begin{array}{l}48 \\
90.6 \%\end{array}$ & $\begin{array}{l}30 \\
100 \%\end{array}$ & $\begin{array}{l}33 \\
91.7 \%\end{array}$ & $\begin{array}{l}29 \\
87.7 \%\end{array}$ \\
\hline Solving farm-related problem & $\begin{array}{l}12 \\
75 \%\end{array}$ & $\begin{array}{l}35 \\
60 \%\end{array}$ & $\begin{array}{l}34 \\
64.2 \%\end{array}$ & $\begin{array}{l}24 \\
80 \%\end{array}$ & $\begin{array}{l}28 \\
77.8 \%\end{array}$ & $\begin{array}{l}20 \\
60 \%\end{array}$ \\
\hline Reporting of observed problems & $\begin{array}{l}9 \\
56.3 \%\end{array}$ & $\begin{array}{l}39 \\
67.2 \%\end{array}$ & $\begin{array}{l}37 \\
69.8 \%\end{array}$ & $\begin{array}{l}21 \\
70 \%\end{array}$ & $\begin{array}{l}33 \\
91.7 \%\end{array}$ & $\begin{array}{l}29 \\
87.7 \%\end{array}$ \\
\hline
\end{tabular}

farmers managed to solve some of the observed farmrelated problems while 147 (68.7\%) reported only observing farm-related problems. More female $(79,69.3 \%)$ than male $(73,66.4 \%)$ rice farmers reported solving farmrelated problems.

The level of performance of some of the agricultural knowledge management activities was found to differ by age of the farmer. Findings in Table 4 indicate that, regardless of their age, all respondents used agricultural knowledge. Findings indicate further that 15 (93.8\%) of the youngest respondents and $33(56.9 \%)$ respondents aged 26 to 35 years mentioned accessing agricultural knowledge.

The trend for accessing agricultural knowledge in other age groups increased from $60.4 \%$ to $70 \%$ (Table 4 ). Moreover, findings indicate that regardless of the age groups more than $88 \%$ of all respondents share agricultural knowledge and observed farm-related problems. On the other hand, reporting farm-related problems to a third person was found to increase by age of the rice farmer (Table 4).

Likewise, findings from focus group discussion indicate that rice farmers accessed, shared and used agricultural knowledge. They also observed different problems on their farms. Some managed to solve them using their long-term experience while others reported them to fellow rice farmers, agricultural input suppliers or agricultural extension agents, in the spirit of information sharing.

Involvement in agricultural management activities was found to differ by the level of education. Findings in Table 5 indicate that using agricultural knowledge was not influenced by level of education. Among respondents with informal education, $13(44.8 \%)$ mentioned to have been accessing knowledge. Likewise, four (80\%), 102 (64.2\%) and $26(78.8 \%)$ respondents with adult, primary and secondary education, respectively, were of the view that they had access to agricultural knowledge.

Nine $(31 \%)$, three $(60 \%), 66(41.9 \%)$ and $24(72.7 \%)$ respondents with informal, adult, primary and secondary level of education, respectively, mentioned sharing agricultural knowledge. Solving observed problems was regarded as slightly increasing with level of education. Moreover, $25(86.2 \%)$, four (80\%), $152(95.2 \%)$ and 30 (90.9\%) respondents with informal, adult, primary and secondary level of education, respectively, mentioned observing farm-related problems. Others, five (31.3\%), two $(66.7 \%), 60(48.8 \%)$ and $12(41.4 \%)$ with informal, adult, primary and secondary level of education, respectively, mentioned to have been reporting farm-related problems to a third party. 
Table 5. Agricultural knowledge management activities performed by rice farmers by level of education.

\begin{tabular}{lllll}
\hline Knowledge management activity & Informal education & Adult education & Primary education & Secondary education \\
\hline Accessing knowledge & $13(44.8 \%)$ & $4(80 \%)$ & $102(64.2 \%)$ & $26(78.8 \%)$ \\
Using knowledge & $29(100 \%)$ & $5(100 \%)$ & $159(100 \%)$ & $33(100 \%)$ \\
Sharing knowledge & $9(31 \%)$ & $3(60 \%)$ & $66(41.8 \%)$ & $24(72.7 \%)$ \\
Observing farm-related problems & $25(86.2 \%)$ & $4(80 \%)$ & $152(95.2 \%)$ & $30(90.9 \%)$ \\
Solving the observed problem & $15(51.7 \%)$ & $3(60 \%)$ & $116(73.9 \%)$ & $18(54.5 \%)$ \\
Reporting of farm-related problems & $05(31.3 \%)$ & $2(66.7 \%)$ & $60(48.8 \%)$ & $12(41.4 \%)$ \\
\hline
\end{tabular}

Table 6. Factors enhancing involvement in agricultural knowledge management activities.

\begin{tabular}{lc}
\hline Factors enhancing involvement in agricultural knowledge management activities & Frequency \\
\hline Individual factors & $153(67.7 \%)$ \\
Ownership of communication tools & $136(60.2 \%)$ \\
Affordability of tariffs & $102(45.1 \%)$ \\
Membership in farmers' groups & $15(6.6 \%)$ \\
Literacy & $217(96 \%)$ \\
Institutional factors & $160(71 \%)$ \\
Availability of agricultural extension services & $154(68 \%)$ \\
Timeliness of radio/television (TV) agricultural programmes & $123(54.4 \%)$ \\
ICT infrastructure & $68(30 \%)$ \\
Reliability of power & $6(2.7 \%)$ \\
Timely access to agricultural inputs & $189(83.6 \%)$ \\
Timely feedback mechanisms & $156(69 \%)$ \\
Knowledge factors & $100(44.2 \%)$ \\
Availability of agricultural knowledge sources & $\mid \mathrm{II}(4.9 \%)$ \\
Language barriers & \\
Timely accessibility of agricultural knowledge & \\
Relevancy of delivered knowledge to activities & \\
\hline
\end{tabular}

\section{Factors influencing farmers' involvement in knowledge management activities}

Rice farmers were asked to mention factors that influenced their involvement in performing agricultural knowledge management activities. Findings in Table 6 indicate that factors can be categorised into individual, institutional and knowledge factors. Individual factors mentioned include ownership of communication tools $(153,67.7 \%)$, affordability of tariffs $(136,60.2 \%)$, membership in farmers' groups $(102,45.1 \%)$ and level of literacy $(15,6.6 \%)$.

Institutional factors were also found to influence the performance of agricultural knowledge management activities. Those mentioned include availability of agricultural extension services $(217,96 \%)$, timeliness of radio/ TV agricultural programmes $(160,71 \%)$ and reliability of power supply $(154,68 \%)$. Others were timely accessibility of farm inputs including seeds, fertilizers, herbicides and pesticides $(68,30 \%)$ and availability of timely feedback communication $(06,2.7)$.

It was also found that some knowledge-related factors were mentioned as influencing the performance of agricultural knowledge factors (Table 6). These factors include the availability of agricultural knowledge sources (189, $83.6 \%)$, language barriers $(156,69 \%)$, timely accessibility of agricultural knowledge $(100,44.2 \%)$ and relevancy of delivered knowledge to activities performed (11, 4.9\%).

Likewise, findings from the focus group discussion indicate access to agricultural extension services, availability of agricultural knowledge sources, level of literacy among farmers and feedback influenced accessing, sharing and using knowledge, broadcasting radio and/or TV agricultural programmes during work hours; late delivery of farm inputs (seeds, fertilizers, herbicides and pesticides) and limited power supply are factors that hinder accessibility of knowledge.

A correlation analysis was run to determine the association between performing agricultural knowledge activities and some variables. Knowledge management activities involved in the correlation analysis are observing farmrelated problems, reporting observed problems, accessing agricultural knowledge and sharing agricultural knowledge. These knowledge management activities were correlated with level of education and membership in farmers' groups. Reporting observed problems, accessing and sharing knowledge were also correlated with ownership of 
Table 7. The influence of some variables on performing relevant agricultural knowledge activities.

\begin{tabular}{|c|c|c|c|c|c|}
\hline $\begin{array}{l}\text { Dependent variable: knowledge } \\
\text { management activities }\end{array}$ & $\begin{array}{l}\text { Spearman's } \\
\text { rho }\end{array}$ & $\begin{array}{l}\text { Level of } \\
\text { education }\end{array}$ & $\begin{array}{l}\text { Owning a } \\
\text { radio set }\end{array}$ & $\begin{array}{l}\text { Owning a } \\
\text { mobile phone }\end{array}$ & $\begin{array}{l}\text { Membership in } \\
\text { farmers' group }\end{array}$ \\
\hline \multirow[t]{3}{*}{ Observing farm-related problems } & $\begin{array}{l}\text { Correlation } \\
\text { Coefficient }\end{array}$ & -.062 & & & -.035 \\
\hline & Sig. (2-tailed) & .355 & & & .597 \\
\hline & $\mathrm{N}$ & 226 & & & 226 \\
\hline \multirow[t]{3}{*}{ Reporting observed problems } & $\begin{array}{l}\text { Correlation } \\
\text { Coefficient }\end{array}$ & $-.289(* *)$ & $.266(* *)$ & $.242(* *)$ & $.182(* *)$ \\
\hline & Sig. (2-tailed) & .000 & .000 & .000 & .000 \\
\hline & $\mathrm{N}$ & 226 & 214 & 226 & 226 \\
\hline \multirow[t]{3}{*}{ Accessing agricultural knowledge } & $\begin{array}{l}\text { Correlation } \\
\text { Coefficient }\end{array}$ & $-.26 I(* *)$ & .108 & .087 & .095 \\
\hline & Sig. (2-tailed) & .000 & .104 & .195 & .155 \\
\hline & $\mathrm{N}$ & 226 & 226 & 226 & 226 \\
\hline \multirow[t]{3}{*}{ Sharing agricultural knowledge } & $\begin{array}{l}\text { Correlation } \\
\text { Coefficient }\end{array}$ & -.056 & .039 & $.217(* *)$ & $.133(*)$ \\
\hline & Sig. (2-tailed) & .156 & .569 & .000 & .045 \\
\hline & $\mathrm{N}$ & 226 & 226 & 226 & 226 \\
\hline
\end{tabular}

*Correlation is significant at the 0.05 level (2-tailed).

${ }^{*}$ Correlation is significant at the 0.01 level (2-tailed).

radio sets and mobile phones. Correlation is significant at 0.05 or 0.01 .

Findings in Table 7 indicate that there is a strong negative correlation (rho $=-.289$ ) at 0.05 level, between the level of education and reporting observed problems. There is also a strong negative correlation at the 0.05 level between accessing agricultural knowledge and farmers' level of education/level of literacy $($ rho $=.261)$. However, there is a strong positive correlation between ownership of a radio set (rho $=.266$ ), ownership of a mobile phone (rho $=.242)$ and membership in farmers' groups (rho $=.182)$ and reporting observed problems, respectively (correlation is significant at the 0.05 level). Likewise, there is a strong positive correlation between two variables, namely owning a mobile phone (rho $=.217$ ) and membership in farmers' groups $($ rho $=.133)$ and sharing agricultural knowledge.

\section{Discussion}

The findings indicate that rice farming in the study area involved $49.1 \%$ male and $50.9 \%$ female rice farmers (Table 2 ). This reflects that in the study area there are slightly more females involved in rice production than males. These findings are supported by a study (Palacios-Lopez et al., 2017) which also found a higher percentage of females in the agricultural labour force in Tanzania than male. Moreover, findings indicate that most of the farmers were aged between 26 and 45. Farmers within the reported age range are strong and have adequate farming experience.

A majority of farmer participants $(70 \%)$ had a primary level of education (Table 2). In Tanzania, primary education is the basic level of education. In primary schools, children are taught basic life skills necessary for sustaining life and generating income. Farmers with a primary level of education reported ability to use knowledge and adopt agricultural technologies and developments. Findings indicate further that only $14.6 \%$ of the rice farmers had a secondary level of education. In Tanzania, agriculture is considered to offer employment to those whose level of education is not above primary education. In most cases, people with secondary and higher education shy away from farming. However, due to the increasing unemployment rates, this trend is decreasing. Moreover, it is evident from Table 2 that more male rice farmers had formal education than female farmers. This is mainly due to the fact that in Tanzania, educational opportunities for females are relatively lower than those for males (Hedges et al., 2016).

The farming experience of the rice farmers varied from one to more than 30 years. The results exhibited that $17.7 \%$ farmers had one to five years' experience in rice farming, $19.5 \%$ had six to 10 years' experience, $12.4 \%$ had 11 to 15 years' experience; while $14.2 \%$ had 16 to 20 years' experience in rice farming. $16.8 \%$ farmers had 21 to 30 years' experience, while $19.5 \%$ had more than 30 years' experience in rice farming. Having farmers with varied farming experience is of great potential for enhancing learning from the experience of others as farmers with less experience can learn from the experienced ones.

\section{Agricultural knowledge management activities conducted by farmers}

Rice farmers were involved in performing different agricultural knowledge activities. The findings in Table 3 indicate 
that $64.2 \%$ of the respondents mentioned accessing agricultural knowledge. Accessing agricultural knowledge is one step towards addressing the knowledge gap for accomplishing a given task. Agricultural knowledge is accessed from different sources, including fellow farmers, agricultural extension agents, libraries and radio programmes (Lwoga, 2010). Findings indicate that $72.1 \%$ of the male and $56.5 \%$ of the female rice farmers mentioned access to agricultural knowledge. It can be found that more male rice farmers than female rice farmers mentioned accessing agricultural knowledge. Results from focus group discussions indicate that most agricultural knowledge sources located away from farmers' residential areas were visited during evening hours after farm activities. During evening hours most female farmers engaged themselves in preparing meals for the family hence limiting accessing agricultural knowledge from such sources. This is in line with the findings of Mtega (2012) who also found that household activities performed by female farmers after farm activities limited them from accessing agricultural knowledge from sources located far away from their residential areas. There were very few agricultural extension agents in the study area (one agent per village) and most of the agents were males. Due to cultural barriers only some female farmers accessed agricultural extension services from male extension agents. This is in line with the findings of Umeta (2013) who found that some female farmers in Ethiopia failed to access agricultural services from some male agents due to cultural limitations. Likewise, participation of women farmers in extension events like training, field days and demonstration is usually very low (McCormack, 2018) because most of such events are conducted in distant places.

Accessing agricultural knowledge was somehow influenced by age and educational level. Findings in Table 4 indicate that most of the young farmers aged between 15 and 25 accessed agricultural knowledge. The level of accessing agricultural knowledge slightly increased with the age of the rice farmer. This shows that farmers' perceptions of the importance of knowledge for performing agricultural activities slightly increased with an increase in the farmer's age. Likewise, perceptions of the importance of agricultural knowledge to perform activities increased with the farmer's level of education (Table 5).

Regardless of their sex, farming experience and level of education, all of the rice farmers involved in the study reported using knowledge while performing different agricultural activities. Rice farmers use knowledge accessed/ acquired from different sources. Among the types of knowledge widely used by farmers is indigenous knowledge (Mwaura, 2008).

The majority of rice farmers $(93.8 \%)$ shared agricultural knowledge with others (Table 4). This indicates that more rice farmers mentioned sharing agricultural knowledge than those who mentioned access to agricultural knowledge (Table 3 and4). This may probably imply that those who did not access agricultural knowledge, shared knowledge acquired through farming experience to others. Moreover, $95.5 \%$ of the male and $92.2 \%$ of the female respondents mentioned sharing agricultural knowledge (Table 3). This is explained by the fact that male farmers have more opportunities of accessing agricultural knowledge from different sources than female farmers (Mtega, 2012). Moreover, the tendency to share agricultural knowledge was found to slightly increase with level of education (Table 5). An increase in level of education may increase the need for knowledge expressed in the form of a request for new skills. This necessitates knowledgeable rice farmers to respond by sharing knowledge.

The findings in Table 4 indicate that $93.4 \%$ of the rice farmers mentioned observing farm-related problems. Being able to identify and observe a problem is an important process towards knowledge creation. Findings indicate that $91.9 \%$ and $94.8 \%$ of the male and female rice farmers reported observing farm-related problems respectively. This is supported by Palacios-Lopez et al. (2017) who also found that more female than male farmers in Tanzania involved themselves in the day-to-day agricultural production activities. This may increase the chances for female farmers to have more farm experience. Moreover, findings in Table 4 indicate that, regardless of their age, the majority of respondents (more than 87\%) mentioned observing farm-related problems. Despite this fact, the trend of observing farm-related problems was found to slightly decline with an increase in age.

Some rice farmers managed to solve problems observed on their farms without consulting a third party. However, findings indicate that there was no uniform trend showing the impacts of demographic characteristics on solving observed farm-related problems.

The findings in Table 3 indicate that $68.7 \%$ of the rice farmers reported an observed problem to a third party. The findings further indicate that $73.6 \%$ of the male and $63.9 \%$ of the female farmers reported the observed farm-related problems. More male farmers reported observed problems, despite the fact that more female farmers performed dayto-day farm activities. This is because male farmers had more platforms and avenues for reporting encountered agricultural problems (Palacios-Lopez et al., 2017). Findings indicate further that $31.3 \%$ of the rice farmers with informal education, $66.7 \%$ with adult education, $48.8 \%$ with primary education and $41.4 \%$ secondary education reported farm-related problems to a third party. These findings indicate that the level of education had an insignificant influence on reporting incidences.

Generally, rice farmers were involved in accessing, sharing and using knowledge. They also observed farmrelated problems and reported them to a third party. As farm-related problems are solved (mainly through research) new knowledge is created. Likewise, when a problem is observed, farmers themselves may devise techniques 
through combining knowledge and determining ways to resolve the problem thus creating new knowledge. Therefore, accessing knowledge, sharing and using it and observing farm-related problems and reporting or resolving them are the farmers' key involvements in agricultural knowledge management in rice farming.

\section{Factors influencing involvement of farmers in agricultural knowledge management activities}

Involvement in agricultural knowledge management activities is influenced by different factors (Table 6). Such factors are categorised into individual, institutional and knowledge factors. However, the findings in Table 3 reveal that cultural factors have some influence on performing agricultural knowledge management activities.

Individual factors. Individual factors influencing the performance of agricultural knowledge management activities are ownership of communication tools, affordability of tariffs, membership in farmers' groups and literacy level. Ownership of communication tools can enhance acquisition and sharing of agricultural knowledge and reporting observed farm-related problems. This is supported by findings from the correlation analysis Table 7, which indicate that there is a strong positive correlation between ownership of communication tools and reporting observed problems. Individual ownership of a communication tools is a precondition for using its services (Kikulwe et al., 2014). Communication tools enhance the accessibility, sharing and reporting farm-related problems. They remove knowledge transfer barriers and enhance the accessibility of knowledge, hence the adoption of new practices.

Likewise, membership in farmers' groups and level of education influence the performance of knowledge management activities. The findings in Table 7 indicate that there is a strong positive relationship between membership in farmers' groups and sharing agricultural knowledge. Farmers are advised to be in groups for easy access to services. Farmers' organisations have a voluntary membership but providers of agricultural knowledge services can reach more farmers when they are in groups than as individuals (Duveskog and Friis-Hansen 2011). This implies that membership in farmers' groups may enhance accessibility, usage and sharing of agricultural knowledge. On the contrary, individual level of education has a negative relationship with accessing agricultural knowledge. This implies that educated farmers feel that they possess adequate knowledge needed for farming activities. Level of education is known to have a strong influence on usage of knowledge rather than enhancing access to knowledge (Ngathou et al., 2006).

Institutional factors. Institutional factors play an important role in enhancing the creation, accessibility, sharing, usage and knowledge exchange. As indicated in Table 6, access to agricultural extension services is important for enhancing the accessibility of new knowledge, which triggers knowledge usage. Agricultural extension services play an important linkage role between different knowledge sources, including agricultural research institutes and farmers (Deneke and Gulti, 2016). Therefore, access to agricultural extension services is very important for stimulating the performance of all agricultural knowledge management activities.

The findings in Table 6 indicate that access to radio/TV agricultural programmes helps farmers to access agricultural knowledge. In Tanzania, there are several local radio and TV stations which are either commercial or non-commercial and may have a national, regional, district or community coverage. Radio/TV agricultural programmes are considered to be an important source of agricultural knowledge among farmers in developing countries (Ango et al., 2013; Uzonna and Gao, 2013). Presentations or discussions by experts and/or extension workers are common techniques used to disseminate agricultural knowledge through radio/TV (Ango et al., 2013). During discussions, farmers may call radio/TV stations and report problems or ask questions to experts. Therefore, enhancing access to agricultural radio/TV programmes is important for stimulating performance of different agricultural knowledge management activities. Likewise, radio/TV stations should make sure that they broadcast agricultural programmes during farmers' convenient time. Adoption of improved crop practices/technologies correlates significantly and positively with timeliness of knowledge (Uzonna and Gao, 2013). Likewise, having an effective feedback mechanism is important for enhancing clarification, understanding and usage of knowledge. The findings in Table 6 indicate that timely feedback mechanisms influenced the performance of agricultural knowledge activities. Feedback provides clarifications and reduces uncertainty, thereby increasing the level of understanding, resulting in greater chances of adoption of good agricultural practices (Prasanna et al. 2014). In most cases, delayed feedback hinders the rate of adoption of good agricultural practices among farmers.

Other institutional factors influencing agricultural knowledge include access and reliability of power supply and timely accessibility of farm inputs (Table 7). Power supply is needed to run ICT tools. The rice farmers used mobile phones, radio and TV sets, which are all power dependent. Access to reliable sources of power is a problem in most rural areas in sub-Saharan Africa and specifically in Tanzania (Adair-rohani et al., 2013). Inadequate power supply limits rice farmers' use of these ICT tools for different agricultural knowledge management activities.

Likewise, timely access to farm inputs (seeds, fertilizers, herbicides, pesticides) stimulates the level of use of acquired agricultural knowledge. Farm inputs for rice production include improved seeds, fertilizers, new 
technologies, developments and herbicides to mention but a few. When these inputs are delivered on time, farmers can adopt them, thereby increasing the level of use of knowledge. Moreover, most packages of farm inputs (seeds, fertilizers, herbicides, pesticides) are accompanied by information describing how they are used hence providing adequate knowledge to rice farmers.

Knowledge factors. Knowledge factors influencing agricultural knowledge management activities include the availability of agricultural knowledge sources, language used, timely accessibility of knowledge and relevancy of delivered knowledge to activities performed. There are several agricultural knowledge sources, including rural information centres, fellow farmers, farmers' group, agricultural extension agents, radio/TV stations and others (Lwoga et al., 2011). Access to these agricultural knowledge sources enhances access to knowledge. Sources found near farmers' residential areas are known to be consulted more than those found far away (Mtega, 2012). Likewise, language through which agricultural knowledge is communicated is important not only for increasing knowledge acquisition, but also for increasing knowledge usage. To enhance understanding, simple and common rather than scientific language should be used for disseminating agricultural knowledge. Indigenous languages should be used to enhance more understanding among local people (Ifukor and Omogor, 2013). Moreover, the knowledge should be made available on time. When delayed, rice farmers fail to use it because rice is a calendar-based crop. Timely provided knowledge makes it possible for more farmers to adopt good agricultural knowledge practices (Uzonna and Gao, 2013). Despite being delivered on time, knowledge delivered should be relevant to agricultural activities being performed at a given time. Farmers only use knowledge relevant to crops grown and to a particular stage of the crop production process.

\section{Knowledge management best practices enhancing access and usage of agricultural knowledge}

It is important to maintain some agricultural knowledge management best practices so as to enhance access, usage, sharing and creation of agricultural knowledge. Each best practice influences the accessibility, usage, sharing and creation of agricultural knowledge. Details of each agricultural knowledge management best practice are found below.

Develop an effective knowledge infrastructure. Having an effective knowledge infrastructure is important for increasing the performance of agricultural knowledge management activities. Knowledge infrastructure enhances the creation and exchange of knowledge among stakeholders.
Some of the components of a knowledge infrastructure are ICT infrastructure, power supply, variety of agricultural knowledge sources and agricultural extension system (Table 6). Others include agricultural research institutions and passable roads. ICTs facilitate the creation and communication of knowledge (Subashini et al., 2012) while power supply is important for running ICTs. Agricultural knowledge sources are access points to be consulted by those in need of knowledge (Shtaltovna, 2015). Moreover, having a good agricultural extension system is important for linking agricultural research and potential users of knowledge (Meijer et al., 2015), while passable roads facilitate the transportation of print reading agricultural materials which can be deposited in rural libraries/rural information centres (knowledge sources).

Involve different stakeholders. Agricultural knowledge management activities involve processes like knowledge acquisition, knowledge creation, knowledge protection, knowledge integration and knowledge dissemination/ sharing/exchange (Lee and Yang, 2000). These processes are performed by different actors, including those who create knowledge, users, those who repackage, organise, store and disseminate it. These activities cannot be performed when some actors are not involved. As found in Table 6, both individuals and institutions have responsibilities necessary for effective agricultural knowledge management. Therefore, involvement of all actors in performing different knowledge management activities is important in agricultural knowledge management.

Use appropriate ICT tools. ICTs are used for communication purposes. Mobile phones, radios and TV sets are mostly used by farmers in developing countries (Aker, 2011; James, 2010; Lwoga, 2010). Usage of these ICTs among farmers is known to significantly reduce communication and information costs (Aker, 2011). Findings in Tables 6 and 7 and those from the focus group discussion indicate that access to ICTs enhance the acquisition and sharing of agricultural knowledge. However, findings from the focus group discussions indicate that mobile phones and radio sets are used by most farmers. Therefore, to have a great impact on performing agricultural knowledge management activities it is important to choose ICTs that are easily accessible and used by farmers.

Enhance an effective agricultural extension and education system. Access to an agricultural extension and education system is important for effective agricultural knowledge management. An agricultural extension system links agricultural research and farmers and enhances access to innovations among farmers (Odongo, 2013). Findings in Table 6 indicate that $96 \%$ of the rice farmers mentioned that access to agricultural extension services influenced how they performed agricultural management activities. These 
findings indicate that rice farmers appreciate the role played by agricultural extension agents in enhancing access to agricultural knowledge and providing agricultural advisory services. Therefore, the public and private sector should strengthen the agricultural extension and education system so as to enhance sustained provision of agricultural extension and advisory services.

Perform knowledge needs assessment. Farmers have many agricultural knowledge needs which can be identified through an agricultural knowledge needs assessment. Findings in Table 6 and those from the focus group discussion indicate that some sources of agricultural knowledge deliver irrelevant knowledge thus limiting the level of usage. Performing knowledge needs assessment helps knowledge providers to have adequate understanding of farmers' knowledge needs prior to enhancing access/disseminating to agricultural knowledge. Understanding farmers' knowledge needs is important in providing needbased agricultural knowledge (Naveed and Anwar, 2013). Therefore, having and adequate understanding of agricultural knowledge needs is important for increasing the level of usage of agricultural knowledge.

Repackage knowledge in right forms. Repackaging agricultural knowledge in the right forms is important for enhancing easiness in acquisition, sharing and usage. Agricultural knowledge should be presented in simple and understandable language. Findings in Table 6 and results from focus group discussion indicate that language barriers hinder understanding of the intended message. Moreover, repackaging knowledge in simple attractive forms can increase the level of usage. For example, during focus group discussion, farmers mentioned they preferred brochures to books. This can be explained by the fact that a brochure itemises procedures and leaves out unnecessary details.

Enhance access to knowledge through multiple sources. Agricultural knowledge can be accessed through different sources such as libraries, agricultural extension agents, agricultural input suppliers, radio/TV stations, research institutes, fellow farmers and mobile phone services providers (Lwoga et al., 2011). Findings from focus group discussion indicate that few knowledge sources are available in rural areas in Tanzania. This limits alternatives from which farmers can access agricultural knowledge hence leading to inadequate access and a low level of usage of agricultural knowledge. Disseminating the same knowledge via different channels and media can increase the reach and therefore its accessibility. This in turn increases the level of usage and sharing of knowledge.

Facilitate immediate feedback mechanism. An immediate feedback mechanism is important for removing doubts and refining recommendations. Among farmers, a feedback mechanism is important when innovations are adopted or tested, to clarify issues raised by farmers during this stage. An effective feedback mechanism helps to remove doubts and enhance mutual understanding between sides in a timely way, thus increasing sharing and usage of knowledge. Findings from focus group discussion indicate that most queries sent for clarifications were not responded to on time, hence limiting the level of usage of agricultural knowledge. Therefore, establishing and maintaining a stable feedback mechanism is important for an effective agricultural knowledge management.

Incorporate indigenous and exogenous knowledge. Indigenous knowledge is developed and accumulated over a long period of time by community members and is passed down over generations mostly by word of mouth (Mugwisi et al., 2014). Indigenous knowledge is learned through phenomenological experience and everyday activities (Bruchac, 2014). In rural areas, indigenous knowledge forms an important component of knowledge when access to exogenous knowledge (knowledge from external sources) is very limited. Results from the focus group discussions reveal that the rice farmers solved some of the farm-related problems through learned experience in farming experience. Farmers may share their learned experiences with fellow farmers. Farmers' learned experiences may be documented after being proven and combined with exogenous knowledge.

Enhance timely access to farm inputs. Access to farm inputs enhances sharing and usage of knowledge on good crop management practices. Findings from focus group discussions reveal that most farmers failed to employ the acquired skills because farm inputs were delivered late. Therefore, timely delivery of farm inputs (seeds, fertilizers, herbicides and pesticides) is important for increased acquisition and usage of agricultural knowledge.

\section{Conclusion}

Effective agricultural knowledge management activities are important for increased adoption of agricultural innovations among rice farmers. With effective agricultural knowledge management, the creation, acquisition, sharing and usage become more effective too. For enhancing effective knowledge management, it is important to develop an effective knowledge infrastructure, involve different stakeholders and use recommended ICTs. Moreover, it is vital to enhance an effective agricultural extension and education system, repackage knowledge in more attractive forms, perform knowledge needs assessment and facilitate immediate feedback mechanism. Multiple sources should be used to enhance access to knowledge with incorporation of indigenous and exogenous knowledge. Moreover, enhancing timely access to farm inputs is also important 
for increased sharing and usage of knowledge. To improve the performance of agricultural knowledge management activities it is recommended that the agricultural knowledge management best practices as proposed by this study should be adopted.

\section{Declaration of conflicting interests}

The author(s) declared no potential conflicts of interest with respect to the research, authorship, and/or publication of this article.

\section{Funding}

The author(s) received no financial support for the research, authorship, and/or publication of this article.

\section{ORCID iDs}

Wulystan Pius Mtega (iD https://orcid.org/0000-0001-8471-1878 Mpho Ngoepe iD https://orcid.org/0000-0002-6241-161X

\section{Reference}

Adair-rohani H, et al. (2013) Limited electricity access in health facilities of sub-Saharan Africa : A systematic review of data on electricity access, sources, and reliability. Global Health: Science and Practice 1(2): 249-261.

Aker JC (2011) Dial 'A' for agriculture: A review of information and communication technologies for agricultural extension in developing countries. Agricultural Economics 42(6): 631-647.

Alsuraihi MD and Bashraheel HO (2013) Information and communication technologies: ICTs in the Saudi household. Journal of Asian Scientific Research 3(3): 286-307.

Ango AK, et al. (2013) Role of farm-radio agricultural programmes in disseminating agricultural technology to rural famers for agricultural development in Zaria, Kaduna State, Nigeria. Asian Journal of Agricultural Extension Economics and Sociology 2(1): 54-68.

Bartlett JE, Kotrlik JW and Higgins CC (2001) Organizational research: Determining appropriate sample size in survey research. Information Technology, Learning, and Performance Journal 19(1): 43-50.

Bernard R, Dulle F and Honesta N (2014) Assessment of the information needs of rice farmers in Tanzania: A case study of Kilombero District, Morogoro. Library Philosophy \& Practice 1071. Available at: http://search.ebscohost.com $/$ login.aspx?direct $=$ true $\& d b=1 x h \& A N=97212802 \&$ site $=$ eh ost-live.

Bruchac M (2014) Indigenous knowledge and traditional knowledge. In: Smith C (ed.) Encyclopedia of Global Archaeology. New York: Springer, pp. 3814-3824.

Butler T and Murphy C (2007) Implementing knowledge management systems in public sector organisations: A case study of critical success factors. In: 15th European conference on information systems (ECIS 2007), pp.612-623. Available at: http://is2.lse.ac.uk/asp/aspecis/20070021.pdf (accessed 10 June 2019).
Claver-Cortés E, Zaragoza-Sáez P and Pertusa-Ortega E (2007) Organizational structure features supporting knowledge management processes. Journal of Knowledge Management. 11(4): 45-57.

Deneke TT and Gulti D (2016) Agricultural research and extension linkages in the Amhara region, Ethiopia. In: Gatzweiler FW and von Braun J (eds) Technological and Institutional Innovations for Marginalized Smallholders. Cham: Springer, pp. 113-124.

Dharmarathna WRSS and Weerakoon SB (2016) Analysis of climate change impacts on rice production: Case study of Kurunegala District, Sri Lanka. In: 8th International perspective on water resources and the environment. American Society of Civil Engineers/Environmental and Water Resources Institute. Sustainable Science 9(1): 103-111.

Dongardive P (2013) Information repackaging in library services. International Journal of Science and Research 2(11): 204-209.

Duveskog D and Friis-Hansen E (2011) Farmer field schools in Rural Kenya: A transformative learning experience. Journal of Development Studies 47(10): 1529-1544.

Elly T and Silayo EE (2013) Agricultural information needs and sources of the rural farmers in Tanzania: A case of Iringa Rural District. Library Review 62(8): 547-566.

Hameed S and Badii A (2012) Effectiveness of knowledge management functions in improving the quality of education in higher education institutions. International Journal of Information and Education Technology 2(4): 319-323.

Harvey CA, et al. (2014) Extreme vulnerability of smallholder farmers to agricultural risks and climate change in Madagascar. Philosophical Transactions of the Royal Society of London. Series B, Biological Sciences 369(1639). DOI: $10.1098 /$ rstb2013.0089.

Hedges S, et al. (2016) Sending children to school: Rural livelihoods and parental investment in education in northern Tanzania. Evolution and Human Behavior 37(2): 142-151.

Ifukor MO (2013) Channels of information acquisition and dissemination among rural dwellers. International Journal of Library and Information Science 5(10): 306-312.

James J (2010) Penetration and growth rates of mobile phones in developing countries: An analytical classification. Social Indicators Research 99(1): 135-145.

Jauniškyte I and Kvaraciejute E (2008) Structure of knowledge management. Global Academic Society Journal: Social Science Insight 1(2): 4-20.

Jayasingam S, Ansari MA and Jantan M (2010) Influencing knowledge workers: The power of top management. Industrial Management and Data Systems 110(1): 134151.

Kamarudin HD, et al. (2015) Exploring knowledge sharing practices among paddy farmers towards building a foundation for knowledge creation. International Journal of Social Science and Humanity 5(1): 112-115.

Kikulwe EM, Fischer E and Qaim M (2014) Mobile money, smallholder farmers, and household welfare in Kenya. PloS one 9(10): e109804.

Krudys K, et al (2011) Knowledge management for efficient quantitative analyses during regulatory reviews. Expert Review of Clinical Pharmacology 4(6): 697-703. 
Labrique AB, et al. (2013) mHealth innovations as health system strengthening tools: 12 common applications and a visual framework. Global Health, Science and Practice 1(2): 160-171.

Lee CC and Yang J (2000) Knowledge value chain. Journal of Management Development 19(9): 783-793.

Lwoga ET (2010) Bridging the agricultural knowledge and information divide: The case of selected telecenters and rural radio in Tanzania. Electronic Journal on Information Systems in Developing Countries 43(6): 1-14.

Lwoga ET, Stilwell C and Ngulube P (2011) Access and use of agricultural information and knowledge in Tanzania. Library Review 60(5): 383-395.

Lyatuu ET, et al. (2016) Does the improvement of productivity of maize and rice reduce poverty? Comparison case study for Tanzania and Togo. Journal of Economics and Sustainable Development 7(2): 2222-2855.

McCormack C (2018) Key factors in the use of Agricultural Extension Services by women farmers in Babati District, Tanzania : The role of societal gender norms. Master's Thesis, Swedish University of Agricultural Sciences, Uppsala. Available at: https://stud.epsilon.slu.se/13367/11 /mccormack_c_180611.pdf (accessed 5 June 2019).

Meijer SS, et al. (2015) The role of knowledge, attitudes and perceptions in the uptake of agricultural and agroforestry innovations among smallholder farmers in sub-Saharan Africa. International Journal of Agricultural Sustainability 13(1): 40-54.

Mercer J, et al. (2009) Integrating indigenous and scientific knowledge bases for disaster risk reduction in Papua New Guinea. Geografiska Annaler. Series B, Human Geography 91(2): 157-183.

Mkonda MY and He X (2016) Production trends of food crops: Opportunities, challenges and prospects to improve Tanzanian rural livelihoods. Natural Resources and Conservation 4(4): 51-59.

Moahi KH (2012) Promoting African indigenous knowledge in the knowledge economy: Exploring the role of higher education and libraries. ASLIB Proceedings 64(5): 540-554.

Mtega WP (2012) Access to and usage of information among rural communities: A case study of Kilosa District Morogoro Region in Tanzania. Partnership: The Canadian Journal of Library and Information Practice and Research 7(1): 1-13.

Mtega WP, Dulle F and Benard R (2013) Understanding the knowledge sharing process among rural communities in Tanzania: A review of selected studies. Knowledge Management and E-Learning 5(2).

Mtega WP, Ngoepe M and Dube L (2016) Factors influencing access to agricultural knowledge : The case of smallholder rice farmers in the Kilombero district of Tanzania. South African Journal of Information Management 18(1): 1-8.

Mugwisi T, Mostert J and Ocholla DN (2014) Access to and utilization of information and communication technologies by agricultural researchers and extension workers in Zimbabwe. Information Technology for Development 21(1): 67-84.

Munyua HM and Stilwell C (2013) Three ways of knowing: Agricultural knowledge systems of small-scale farmers in Africa with reference to Kenya. Library and Information Science Research 35(4): 326-337.
Mwaura P (ed.) (2008) Indigenous Knowledge in Disaster Management in Africa. Nairobi: United Nations Environment Programme (UNEP).

National Bureau of Statistics (NBS) (2013) Key Findings 2011/12 Household Budget Survey. Dar es Salaam: Ministry of Finance. Available at: http://catalog.ihsn.org/index.php /catalog/4846/download/60556 (accessed 10 June 2019).

Naveed MA and Anwar MA (2013) Agricultural information needs of Pakistani farmers. Malaysian Journal of Library and Information Science 18(3): 13-23.

Ngathou IN, Bukenya JO and Chembezi DM (2006) Managing agricultural risk: Examining information sources preferred by limited resource farmers. Journal of Extension 44(6). Available at: http://www.scopus.com/inward/record .url?eid=2-s2.0-33845993944\&partnerID $=40 \& \mathrm{md5}=\mathrm{d} 5 \mathrm{bf} 4$ f351c64a3aa718711f9f898ce32.

Nkuba J, et al. (2016) Rice value chain analysis in Tanzania: Identification of constraints, opportunities and upgrading strategies. African Crop Science Journal 24(Supplement): 73-87.

Nonaka I, Toyama R and Konno N (2000) SECI, Ba and leadership : A Uni ${ }^{\circledR}$ ed model of dynamic knowledge creation. Leadership 33(1): 5-34.

Odongo D (2013) Agricultural information access among smallholder farmers: Comparative assessment of peri-urban and rural settings in Kenya. Agricultural Information Worldwide 6: $133-137$

Olaniyi OA (2013) Assessment of utilization of information and communication technologies ( ICTS ) among poultry farmers in Nigeria: An emerging challenge. Transnational Journal of Science and Technology 3(6): 361-369.

Palacios-Lopez A, Christiaensen L and Kilic T (2017) How much of the labor in African agriculture is provided by women? Food Policy 67: 52-63.

Prasanna CL, Rani VS and Vasantha R (2014) A study on factors influencing the extent of participation by respondents in feedback mechanism in agricultural technology management. Journal of Research ANGRAU 42(1): 63-65.

Richter A, et al. (2013) Knowledge management goals revisited. Vine 43(2): 132-148.

Sanchez PA (2002) Ecology. Soil fertility and hunger in Africa. Science 295(5562): 2014-2020.

Schut M, et al. (2015) RAAIS: Rapid appraisal of agricultural innovation systems (Part II). Integrated analysis of parasitic weed problems in rice in Tanzania. Agricultural Systems 132(1): 2-24.

Shtaltovna A (2015) Knowledge gaps and rural development in Tajikistan: Agricultural advisory services as a panacea? Journal of Agricultural Education and Extension 11(1): 25-41.

Singh RK, et al. (2014) Farmers' knowledge and creativity in eco-friendly pest management: Lessons in sustainable agriculture. Indian Journal of Traditional Knowledge 13(3): 574-581.

Stadlinger N, et al. (2011) Pesticide use among smallholder rice farmers in Tanzania. Environment, Development and Sustainability 13(3): 641-656.

Stausberg J, et al. (2003) Comparing paper-based with electronic patient records: Lessons learned during a study on diagnosis and procedure codes. Journal of the American Medical Informatics Association 10(5): 470-477. 
Subashini R, Rita S and Vivek M (2012) The role of ICTs in knowledge management (KM) for organizational effectiveness. In: International conference on computing and communication systems, ObCom 2011, pp. 542-549. Berlin, Heidelberg: Springer. Available at: http://link.springer.com/10.1007/978-3642-29216-3_59 (accessed 28 August 2017).

Terdoo F and Feola G (2016) The vulnerability of rice value chains in Sub-Saharan Africa: A review. Climate 4(3): 47.

Umeta G (2013) Analysis of female headed households' participation in agricultural extension package program in East Showa Zone, Ethiopia. American Journal of Research Communication 1(8): 227-245.

Uzonna UR and Gao Q (2013) Effect of extension programs on adoption of improved farm practices by farmers in Adana, Southern Turkey. Journal of Biology,Agriculture and Healthcare 3(15): 17-24.

\section{Author biographies}

Wulystan Pius Mtega is senior lecturer at the Sokoine University of Agriculture in Tanzania. His areas of interest are knowledge management systems and records management systems. He has written several publications in knowledge management. Mtega has also been involved in a number of knowledge management system projects in Tanzania.

Mpho Ngoepe is a professor in the Department of Information Science at the University of South Africa (Unisa). Prior to his current position at Unisa, professor Ngoepe has worked for the United Nations Children's Fund, Auditor-General South Africa and the National Archives of South Africa. Professor Ngoepe served on the national committee of the South African Society of Archivists (2009-2017) and the board of Eastern and Southern Regional Branch of the International Council on Archives (2009-2017) as the editor of the journals. He also serves on the advisory council of the National Archives of South Africa and Gauteng Provincial Archives as the Chairperson. He was the director of the African Team for the multi-national, interdisciplinary research project exploring issues concerning digital records called the International Research on Permanent Authentic Records in Electronic Systems (InterPARES Trust) (2013-2018). 